\title{
The Burden of Invasive Vaccine-Preventable Diseases in Adults in the Middle East and North Africa (MENA) Region
}

\author{
Abdul Rahman Bizri · Abdulhakeem Althaqafi - Nawal Kaabi · \\ Nathir Obeidat $\cdot$ Nadine Al Akoury $\cdot$ Hammam Haridy
}

Received: September 23, 2020 / Accepted: February 19, 2021 / Published online: March 22, 2021

(c) The Author(s) 2021

\begin{abstract}
Implementing vaccination programmes at the national level is key to managing vaccinepreventable diseases (VPDs) in the overall population. Although paediatric immunization
\end{abstract}

Supplementary Information The online version contains supplementary material available at https:// doi.org/10.1007/s40121-021-00420-y.

A. R. Bizri

American University of Beirut Medical Center, Beirut, Lebanon

A. Althaqafi

Department of Medicine, Ministry of National Guard-Health Affairs, Jeddah, Saudi Arabia

A. Althaqafi

King Saud bin Abdulaziz University for Health Sciences, Jeddah, Saudi Arabia

A. Althaqafi ( $\square)$

King Abdullah International Medical Research

Centre, Jeddah, Saudi Arabia

e-mail: ahthaqafi@yahoo.com

N. Kaabi

Abu Dhabi Health Services Company, Abu Dhabi, United Arab Emirates

N. Obeidat

University of Jordan, Amman, Jordan

N. Al Akoury

Pfizer Inc, Beirut, Lebanon

H. Haridy

Pfizer Inc, Dubai, United Arab Emirates programmes have significantly reduced the burden of VPD, disease burden in adults still poses a substantial challenge, particularly in low- and middle-income countries such as those within the Middle East and North Africa (MENA) region. Invasive bacterial diseases (IBDs) are an important public health concern within this region, although vaccines are available to prevent the three most common causative organisms associated with IBD: Neisseria meningitidis (NM), Streptococcus pneumoniae (SP), and Haemophilus influenzae (HI). For this review, three separate PubMed searches were used to identify English-language publications describing the epidemiology of NM, SP, and $\mathrm{HI}$ in adults within the MENA region. Of the 161 total publications retrieved among all 3 literature searches, 39 were included in this review (NM: 8 publications; SP: 27 publications; HI: 4 publications). Publications describing epidemiology in paediatric or overall populations were excluded. Overall, these studies generally observed a high burden of IBD among adults in this region. Although NM, SP, and HI are communicable diseases in several countries, the surveillance systems in the MENA region are largely inadequate, resulting in poor responses to outbreaks and hindering improvement in outcomes of communicable diseases. Improving IBD surveillance would provide necessary estimates of disease burden, resulting in better vaccination strategies and improved outcomes. In conclusion, the present review provides a 
summary of the available information on the epidemiology of vaccine-preventable IBD in adults within the MENA region and highlights the need for increased disease surveillance and preventive strategies in these countries.

Keywords: Epidemiology; Haemophilus influenzae; Invasive bacterial disease; Middle East and North Africa (MENA); Neisseria meningitidis; Streptococcus pneumoniae

\section{Key Summary Points}

Invasive bacterial diseases, such as Neisseria meningitidis, Streptococcus pneumoniae, and Haemophilus influenzae, are important public health concerns in many countries

Most countries in the Middle East and North Africa region have insufficient or no surveillance systems in place to monitor invasive bacterial diseases

Implementing national vaccination strategies, based on improved and comprehensive surveillance data, could contribute to reducing the burden of invasive bacterial diseases within the region

\section{DIGITAL FEATURES}

This article is published with digital features, including a summary slide, to facilitate understanding of the article. To view digital features for this article go to https://doi.org/10.6084/ m9.figshare.14055101.

\section{INTRODUCTION}

Globally, vaccination is an important public health intervention that has cost-effectively averted approximately 2.5 million annual deaths in children younger than 5 years [1]. In many nations, routine vaccination programmes target infants and children, with fewer countries providing recommendations specifically for adults [2]. Although paediatric immunization programmes have successfully lowered the overall burden of many vaccine-preventable diseases (VPDs), the adult population accordingly represents a substantial disease burden [3-5]. With an ageing global population, adult disease burden is predicted to increase substantially in the coming years [3]. As vaccination uptake among adults is typically lower compared with younger age groups [4], a growing need exists to focus on sufficiently protecting this population. This is particularly critical in low- and middle-income countries, as vaccination policies for adults are not widely implemented [2], and VPDs remain a significant health burden [4]. This disparity is partly due to poor access to health facilities, insufficient funding for vaccination programmes, and general economic challenges for patients $[6,7]$.

The Middle East and North Africa (MENA) region comprises countries of varying socioeconomic status, including multiple low- and middle-income countries [8,9]. Although certain countries in MENA are eligible for assistance from Gavi, the Vaccine Alliance (e.g., Syria and Yemen), the majority of countries in this region face economic hurdles for vaccine procurement. An understanding of adult disease burden within MENA can also be limited or underestimated, as surveillance reporting on VPD in this large geographic area can vary by country in part because of differing socioeconomic constraints [10]. Therefore, a critical need exists for understanding the epidemiology of adult VPD in MENA to guide vaccination strategies and reduce disease burden.

Of the vaccine-preventable causes of disease, three can result in invasive bacterial disease (IBD), namely Neisseria meningitidis (NM), Streptococcus pneumoniae (SP), and Haemophilus influenzae (HI), which are important public health issues in many countries, particularly among those at the extremes of ages [11-14]. Septicaemia and meningitis are the most common manifestations of IBD; they have a high mortality rate and can cause permanent 
sequelae, including amputation, neurological effects, tissue damage, and organ failure [11].

In the context of the importance of ascertaining the epidemiology of VPD, this narrative review summarizes available information on vaccine-preventable IBD among adults in the MENA region. These data are then considered in the context of current national vaccination policies and surveillance strategies for IBD in
MENA, and recommendations for future study and programme implementations are provided.

\section{METHODS}

Three PubMed searches identified English-language publications describing the epidemiology of NM, SP, and HI among adults in MENA using the search terms outlined in Table 1 . The

Table 1 Search strings

\begin{tabular}{|c|c|}
\hline Search & Search string \\
\hline \multirow[t]{10}{*}{ N. meningitidis } & $\left(\left(\left(\left(\left({ }^{\prime}\right.\right.\right.\right.\right.$ Neisseria meningitidis” OR “N meningitidis” OR “IMD” OR “Invasive meningococcal disease”)) \\
\hline & AND (“Algeria” OR “Bahrain” OR “Djibouti” OR “Egypt” OR “Iran” OR “Iraq” OR “Jordan” OR \\
\hline & "Kuwait" OR "Lebanon" OR "Libya" OR "Morocco" OR "North Africa" OR "Northern Africa" OR \\
\hline & "Middle East and North Africa" OR "Oman" OR "Palestine" OR "Qatar" OR "Saudi Arabia" OR \\
\hline & “Syria” OR “Tunisia” OR “Turkey” OR “United Arab Emirates” OR “UAE” OR “Yemen”)) AND \\
\hline & (“Epidemiology" OR “Burden” OR "Prevalence” OR “Incidence" OR “Mortality” OR “Morbidity” \\
\hline & OR “Death" OR “Fatality" OR “Fatalities" OR “Cases” OR “CFR” OR “Surveillance” OR \\
\hline & "Notification" OR "Outbreak" OR “Antibiotic resistance" OR “Antimicrobial resistance” OR \\
\hline & “resistance” OR “antibiotic" OR “antimicrobial” OR “AMR”)) AND Adult) AND \\
\hline & English[Language]) AND (“2010/01/01”[Date-Publication]: “3000”[Date-Publication]) \\
\hline
\end{tabular}

S. pneumoniae $\quad((((($ “Pneumococci” OR “Pneumococcus” OR “S pneumoniae” OR "Streptococcus Pneumoniae”)) AND (“Algeria” OR “Bahrain” OR “Djibouti” OR “Egypt” OR “Iran” OR “Iraq” OR “Jordan” OR "Kuwait" OR "Lebanon" OR "Libya” OR "Morocco" OR "North Africa” OR "Northern Africa” OR "Middle East and North Africa" OR "Oman" OR "Palestine" OR "Qatar" OR "Saudi Arabia” OR “Syria” OR “Tunisia” OR “Turkey” OR “United Arab Emirates” OR “UAE” OR “Yemen”)) AND ("Epidemiology" OR "Burden” OR "Prevalence” OR "Incidence” OR "Mortality" OR "Morbidity" OR "Death" OR "Fatality" OR "Fatalities" OR "Cases" OR “CFR" OR “Surveillance” OR "Notification" OR “Outbreak" OR "Antibiotic resistance" OR "Antimicrobial resistance” OR “resistance” OR "antibiotic" OR “antimicrobial” OR “AMR”)) AND Adult) AND English[Language]) AND (“2010/01/01”[Date-Publication]: “3000”[Date-Publication])

H. influenzae $\quad((((($ “H influenzae” OR “Haemophilus influenzae” OR "Hib”)) AND (“Algeria” OR "Bahrain” OR “Djibouti” OR “Egypt” OR “Iran” OR “Iraq” OR “Jordan” OR “Kuwait” OR “Lebanon” OR “Libya” OR "Morocco" OR "North Africa” OR "Northern Africa” OR "Middle East and North Africa” OR “Oman” OR “Palestine” OR "Qatar” OR “Saudi Arabia” OR “Syria” OR “Tunisia” OR “Turkey” OR “United Arab Emirates" OR “UAE” OR “Yemen”)) AND (“Epidemiology” OR "Burden” OR "Prevalence” OR “Incidence” OR "Mortality” OR “Morbidity” OR “Death” OR “Fatality” OR "Fatalities" OR "Cases" OR "CFR" OR "Surveillance" OR "Notification” OR "Outbreak" OR "Antibiotic resistance" OR "Antimicrobial resistance" OR "resistance” OR "antibiotic" OR “antimicrobial” OR “AMR”)) AND Adult) AND English[Language]) AND (“2010/01/01”[DatePublication]: “3000”[Date-Publication])

PubMed search conducted on January 12, 2020 
countries/states in the search were the combined ones included in the United Nations International Children's Fund (UNICEF) and World Bank MENA definitions, with the exclusion of Israel and Malta, which are part of the World Bank definition but are defined as advanced economies by the International Monetary Fund [15-17]. The literature search was limited to English-language publications from 2010 to January 12, 2020.

Publications were reviewed to identify those reporting NM, SP, and/or HI epidemiology data in adults within a MENA country (e.g., incidence, prevalence, mortality). Information on antimicrobial resistance (AMR) was not considered as part of the literature review. Publications not reporting epidemiological data specifically in adults (i.e., instead reporting data in the general population or only in paediatrics) were excluded, as were publications reporting these data in special populations, in pilgrims, or from case reports or clinical studies.

The article is based on previously conducted studies and does not contain any studies with human participants or animals performed by any of the authors.

\section{BACKGROUND}

\section{Neisseria meningitidis}

Despite the availability of vaccines against the most common disease-causing meningococcal serogroups (i.e., A, B, C, W, Y) [13], invasive meningococcal disease (IMD) remains a global health concern [18]. Worldwide, $>1.2$ million annual cases of IMD are reported [18]. The overall case fatality rate (CFR) for IMD is $5-10 \%$ but can be as high as $9.1-26.4 \%$ in nonindustrialized regions. Furthermore, mortality is generally highest in adults aged $\geq 65$ years [19]. In MENA, NM is considered a leading cause of bacterial meningitis [10], one of the most common clinical presentations of IMD [18]. IMD epidemiology in the region is influenced by multiple factors, including seasonal weather patterns and its geographic proximity to the sub-Saharan African meningitis belt [10], and represents the highest worldwide burden of meningococcal meningitis [20]. Importantly, meningococcal disease is dynamic, with the prevalence of each meningococcal serogroup varying geographically and over time. A recent review of global IMD surveillance from 2010 to 2016 indicated that serogroups $\mathrm{W}$ and $\mathrm{B}$ are predominant in Africa and Europe; notably, the majority of countries in the MENA region were not included in this review [21].

\section{Streptococcus pneumoniae}

Pneumococcal infections affect all ages, but older adults and infants are generally most at risk [22, 23]. Following pneumococcal conjugate vaccine $(\mathrm{PCV})$ introduction, alterations in the age distribution of invasive pneumococcal disease (IPD) have been observed. For example, before 2000 in the USA, IPD incidence was highest in children aged $<5$ years and had a smaller peak in adults aged $\geq 65$ years [22]. By 2017, IPD was most common in individuals aged $\geq 50$ years, with incidence and mortality rates steadily increasing from 16.6 and 1.86 per 100,000, respectively, in those aged 50-64 years, to 41.8 and 9.56 per 100,000 in those aged $\geq 85$ years, with a smaller peak of disease present in infants (incidence and mortality rates of 11.6 and 0.72 per 100,000 , respectively) [24]. IPD is also currently a major cause of morbidity and mortality in adults aged 18 to 64 years with underlying chronic or immunocompromising conditions $[25,26]$.

\section{Haemophilus influenzae}

In the era preceding introduction of HI serotype B (Hib) vaccination, Hib was the most frequent cause of nonepidemic bacterial meningitis in children globally [27]. The impact of vaccination has been immense; in countries achieving high coverage with three- or four-dose $\mathrm{Hib}$ vaccine schedules in the infant national immunization programme (NIP), the overall incidence of invasive $\mathrm{Hib}$ disease has fallen by $>90 \%$. Studies have also shown that the prevalence of $\mathrm{Hib}$ carriage in children has decreased to $<1 \%$ in the vaccine era [28]. Furthermore, substantial shifts in the epidemiology 
of invasive HI disease have been observed, with nontypeable HI (NTHi) becoming the main pathogenic lineage in post-Hib vaccination settings [29-31]. In contrast to Hib, which in the prevaccine era caused invasive disease mostly in healthy children aged $<5$ years, invasive NTHi infections occur mainly in neonates and the elderly and commonly in the presence of predisposing medical conditions [32].

\section{RESULTS}

\section{Neisseria meningitidis}

Of the 30 articles retrieved in the NM literature search, 8 were included in the analysis ( 2 publications each from Iran [33, 34] and Turkey $[35,36]$ and single publications from Egypt [37], Kuwait [38], Saudi Arabia [39], and Yemen [40])

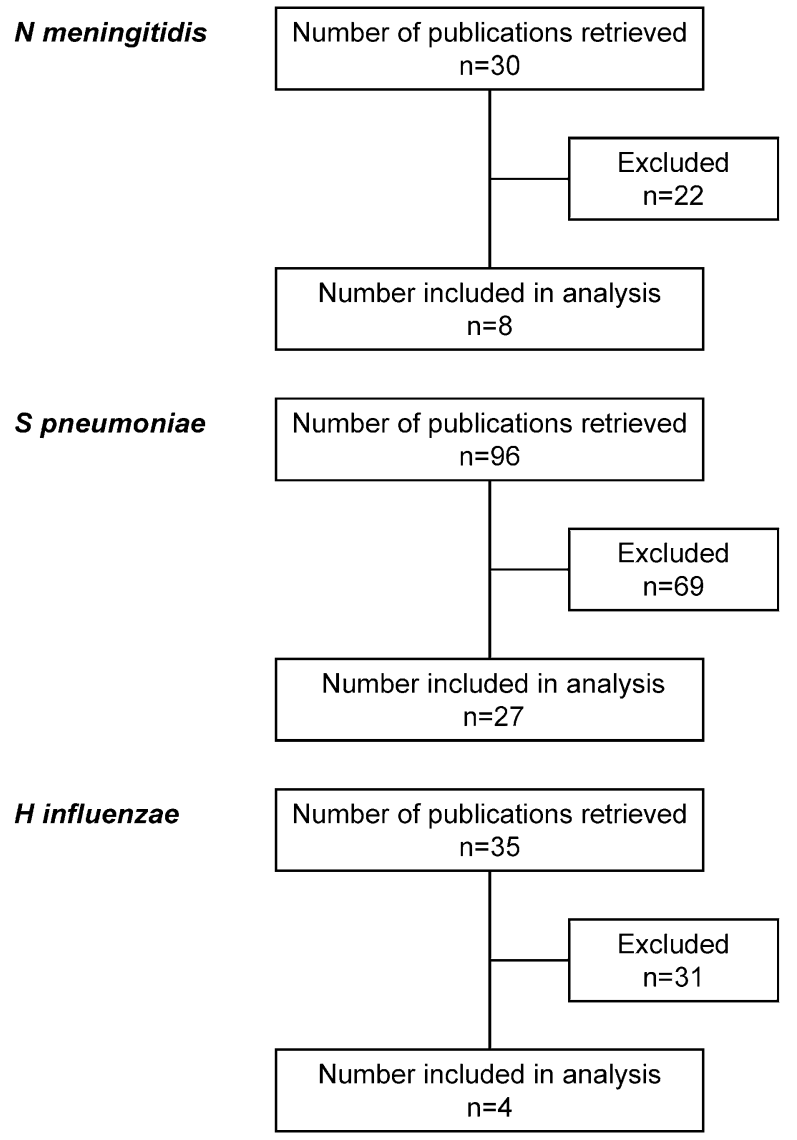

Fig. 1 Summary of literature search results
(Fig. 1; Table 2). Of the identified publications, two were based on national surveillance $[38,39]$, with the remaining being smaller studies (e.g., hospital/school based) [33-37]. Five studies reported on disease epidemiology $[33,37-40]$ and three on carriage epidemiology [34-36] for NM among adults in MENA.

The two national studies identified in the literature search from Kuwait and Saudi Arabia are most informative regarding the epidemiology of meningococcal disease within the MENA region $[38,39]$. In the first study, whereas infants and children represented the largest percentages of meningococcal disease cases occurring from 1987 to 2003 in Kuwait, those aged $\geq 14$ years were also at considerable risk, with nearly onethird of cases occurring in this age group [38]. This study found an $82 \%$ decreased incidence in meningococcal disease across the entire population over the prior 27 years, corresponding to implementation of national surveillance activities. Routine meningococcal vaccination of children and vaccination of pilgrims and labourers were thought to contribute to this reduction.

In the second national study, which evaluated the epidemiology of IMD in Saudi Arabia from 1995 to 2011, epidemiological effects following a change in the Kingdom's vaccination policy in response to two serogroup W IMD outbreaks in 2000 and 2001 were evaluated [39]. Specifically, in 2002, individuals aged $\geq 2$ years living in Mecca and Medina or attending the Hajj, as well as healthcare workers and government personnel serving pilgrims, were to receive the quadrivalent meningococcal (MenACWY) polysaccharide vaccine; the policy was revised in 2010 to include a MenACWY conjugate vaccine for those aged 2-55 years encompassing these same general populations. Before the outbreak, the mean annual IMD incidence was 0.20 per 100,000 ; this increased to $1.32-1.42$ per 100,000 in the outbreak [39]. Following initiation of the vaccination policy, the mean annual incidence was $\leq 0.06$ per 100,000 . Men aged $15-64$ years were at higher risk than women of the same age range (cumulative incidence: 1.8 vs. 0.6 cases per 100,000, respectively). Whereas children aged $<4$ years had the highest disease incidence among citizens and residents, the mean age of 
Table 2 Summary of studies for Neisseria meningitidis

\begin{tabular}{|c|c|c|c|c|}
\hline Country & References & Study date & Population & Summary \\
\hline Egypt & $\begin{array}{l}\text { Mobarak } \\
\text { et al. } \\
\text { [37] }\end{array}$ & $1997-2006$ & $\begin{array}{l}1210 \text { meningitis cases at Alexandria } \\
\text { Communicable Diseases Hospital }\end{array}$ & $\begin{array}{l}\text { N. meningitidis was the causative pathogen in } \\
43 \% \text { and } 50 \% \text { of cases aged } 18-60 \text { and }>60 \\
\text { years, respectively }\end{array}$ \\
\hline \multirow[t]{2}{*}{ Iran } & $\begin{array}{l}\text { Heydari } \\
\text { et al. } \\
\text { [33] }\end{array}$ & $2007-2010$ & $\begin{array}{l}36 \text { adults with confirmed diagnosis of } \\
\text { community-acquired meningitis treated } \\
\text { at Tehran University of Medical Sciences }\end{array}$ & $\begin{array}{l}\text { N. meningitidis isolated from } 27.8 \% \text { of sterile } \\
\text { isolates }\end{array}$ \\
\hline & $\begin{array}{l}\text { Sadeghi } \\
\text { et al. } \\
\text { [34] }\end{array}$ & $\begin{array}{l}\text { Oct } 2017- \\
\quad \text { March } \\
2018\end{array}$ & $\begin{array}{l}335 \text { male students at Kerman University of } \\
\text { Medical Sciences }\end{array}$ & $\begin{array}{l}\text { Carriage rate: } 6.9 \% \\
\text { Carriage rate highest in those aged } 22 \text { years } \\
(21.7 \%) ; 70 \% \text { of carriers were aged } 19-22 \text { years } \\
43.5 \% \text { of carriage isolates were MenC; remaining } \\
\text { were indeterminate } \\
\text { Cigarette smoking significantly associated with } \\
\text { carriage (multivariate analysis) with a fivefold } \\
\text { increased risk compared with nonsmokers } \\
\text { estimated (OR, 5.02; 95\% CI, 1.89-13.35) }\end{array}$ \\
\hline Kuwait & $\begin{array}{l}\text { Husain } \\
\text { et al. } \\
{[38]}\end{array}$ & $1987-2013$ & National population-based surveillance data & $\begin{array}{l}293 \text { cases reported } \\
\text { Mean annual incidence: } 0.5 \text { per } 100,000 \\
\text { Adults aged } \geq 20 \text { years accounted for } 26 \% \text { of all } \\
\text { cases; } 30 \% \text { of cases in individuals aged }>14 \\
\text { years }\end{array}$ \\
\hline $\begin{array}{l}\text { Saudi } \\
\text { Arabia }\end{array}$ & $\begin{array}{l}\text { Memish } \\
\text { et al. } \\
\text { [39] }\end{array}$ & $1995-2011$ & $\begin{array}{l}\text { All IMD cases in the national surveillance } \\
\text { data }\end{array}$ & $\begin{array}{l}\text { Mean annual incidence in the general population } \\
\text { (per 100,000): } 0.20 \text { (1995-1999; before } \\
\text { outbreak), 1.32-1.42 (2000-2001; } \\
\text { outbreak), } \leq 0.06 \text { (2002-2011; following } \\
\text { MenACWY vaccination policy) } \\
\text { Mean age of cases (1995-2011): } 25.8 \text { years } \\
\text { Most common serogroups (aged } \geq 15 \text { years): W, } \\
\text { 45\%; A, } 42 \% \\
\text { CFR: aged > } 45 \text { years, } 32.57 \% \text {; aged } 15-45 \\
\text { years, } 19.41 \%\end{array}$ \\
\hline
\end{tabular}


Table 2 continued

\begin{tabular}{|c|c|c|c|c|}
\hline Country & References & Study date & Population & Summary \\
\hline \multirow[t]{2}{*}{ Turkey } & $\begin{array}{l}\text { Kadayifci } \\
\text { et al. } \\
\text { [35] }\end{array}$ & $\begin{array}{l}\text { June } \\
\text { 2012-Dec } \\
2013\end{array}$ & $\begin{array}{l}1000 \text { healthy subjects aged } 0-79 \text { years in } \\
\text { Istanbul }\end{array}$ & $\begin{array}{l}\text { Carriage rate: } 0.6 \% \text { (all in subjects aged } 21-40 \\
\text { years) } \\
\text { Serogroup B most common }(5 / 6)\end{array}$ \\
\hline & $\begin{array}{l}\text { Tekin et al. } \\
\text { [36] }\end{array}$ & $\begin{array}{l}\text { Jan } \\
\text { 2015-May } \\
2015\end{array}$ & $\begin{array}{l}1518 \text { individuals aged } 10-24 \text { years from } 12 \\
\text { provinces }\end{array}$ & $\begin{array}{l}\text { Carriage rate: } 6.3 \% \text { (overall); } 4.9 \% \text { (age } 10-14 \\
\text { years); } 6.4 \% \text { (age } 15-17 \text { years); } 4.6 \% \text { (age } \\
18-20 \text { years); } 9.1 \% \text { (age } 21-24 \text { years; } P<0.05 \\
\text { vs. other age groups) } \\
\text { Rates of being household contacts in age } 21-24 \\
\text { years group higher for carriers vs. noncarriers } \\
\text { (16.2\% vs. } 5.7 \% ; P<0.05 \text { ) }\end{array}$ \\
\hline Yemen & $\begin{array}{l}\text { Abdulrab } \\
\text { et al. } \\
\text { [40] }\end{array}$ & $\begin{array}{l}\text { Jan } \\
2006-\text { Dec } \\
2007\end{array}$ & $\begin{array}{l}121 \text { patients aged } \geq 15 \text { years treated for } \\
\text { bacterial meningitis at Al-Thawra } \\
\text { Teaching Hospital }\end{array}$ & $\begin{array}{l}\text { N. meningitidis identified in } 20 \text { patients, of } \\
\text { which } 4 \text { cases were fatal }\end{array}$ \\
\hline
\end{tabular}

CFR case fatality rate, IMD invasive meningococcal disease, MenA meningococcal serogroup A, MenACWY quadrivalent meningococcal vaccine, $M e n B$ meningococcal serogroup B, MenW meningococcal serogroup W, $O R$ odds ratio

all cases over the study period showed adults to be at highest risk of IMD (mean age, 25.8 years). The most common serogroups in adults aged $\geq 15$ years were $\mathrm{W}(45 \%$ [160/353]) and A (42\%; [149/353]). The CFR was highest in adults aged $>45$ years $(32.6 \%)$, followed by those aged $15-45$ years $(19.4 \%)$ and was lowest in infants (6.8\%).

The remaining studies describing the epidemiology of meningococcal disease among adults in MENA contained small sample sizes, thereby limiting interpretation; however, these are generally supportive of the considerable burden of meningococcal disease among adults in the region $[33,37,40]$. These studies assessed adults with meningitis, with $\mathrm{NM}$ identified as the causative pathogen in $17-50 \%$ of patients or isolates.

Acquisition of meningococci in the nasopharynx is the initial step required for development of IMD, which arises in some colonized individuals $[41,42]$. Three studies reported on meningococcal carriage in adult populations in MENA, with carriage rates between 0.6 and $9.1 \%$ [34-36]. The most commonly identified meningococcal carriage serogroups included serogroup B (5 of 6 carriage isolates) in one study and serogroup C
(43.5\%) and indeterminate in the remaining study $(56.5 \%)$ [34, 35]. Two studies identified cigarette smoking and being a household contact of pilgrims as associated with being a carrier $[34,36]$.

\section{Streptococcus pneumoniae}

Of the 96 articles retrieved in the SP literature search, 27 included data in adults in MENA and were thus included in the analysis (Fig. 1; Table 3). Across these publications, data were provided for Algeria $(n=1)$ [43], Egypt $(n=5)$ [43-47], Iran $(n=2)$ [48, 49], Kuwait $(n=3)$ [50-52], Lebanon $(n=3)$ [53-55], Morocco $(n=2)[43,56]$, Oman $(n=1)$ [57], Saudi Arabia $(n=2)$ [51, 58], Tunisia $(n=6)$ [43, 59-63], Turkey $(n=5)$ [64-68], and Yemen $(n=1)$ [40].

Only five studies reported population-based epidemiological data regarding SP in adults $[50-52,55,57]$. The most recent was a study from Oman from 2014 to 2016 using data on IPD cases from the national pneumococcal surveillance programme [57]. Notably, the 13-valent PCV (PCV13) was introduced in the NIP for infants in 2012, with the 23-valent polysaccharide pneumococcal vaccine (PPSV23) 


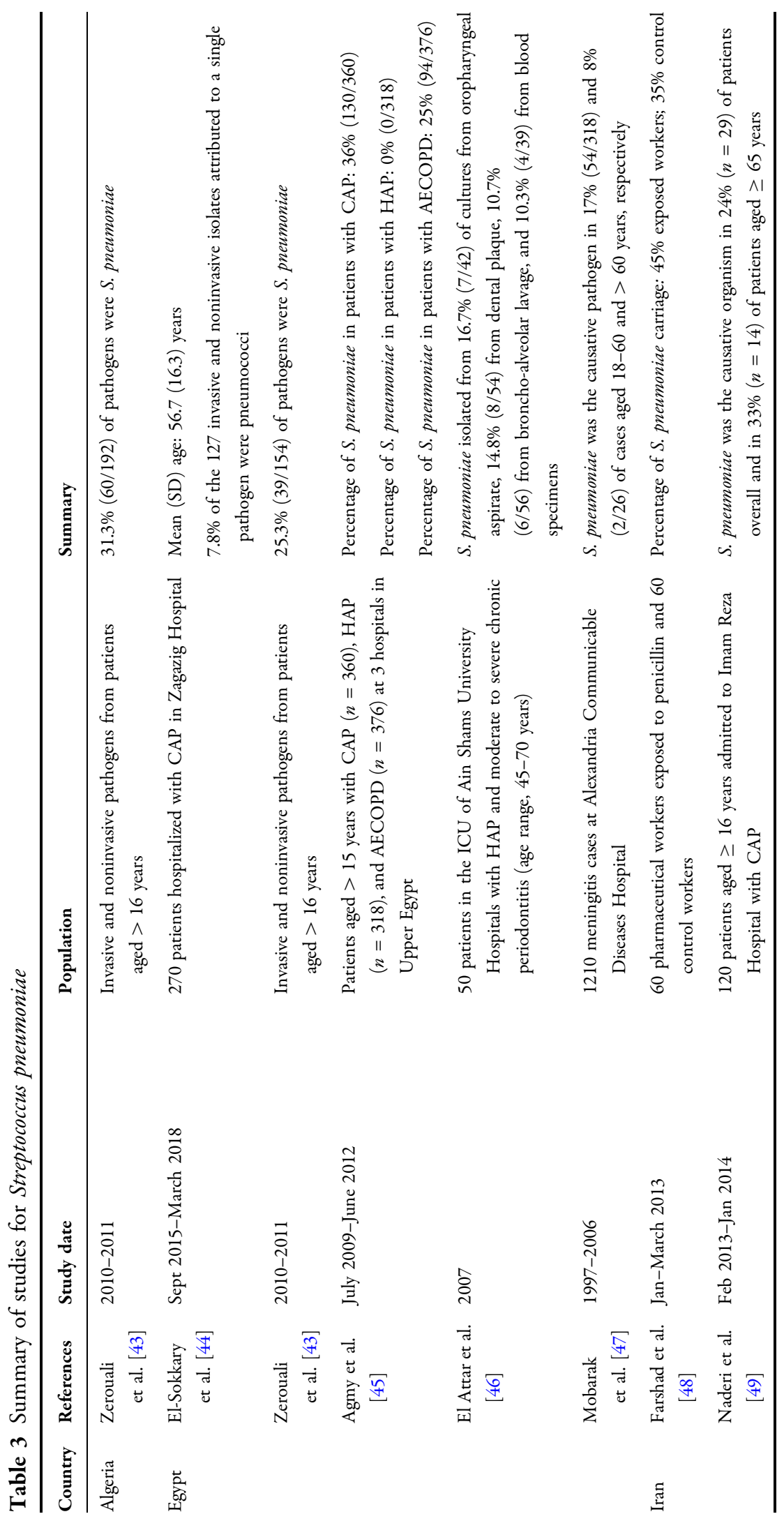




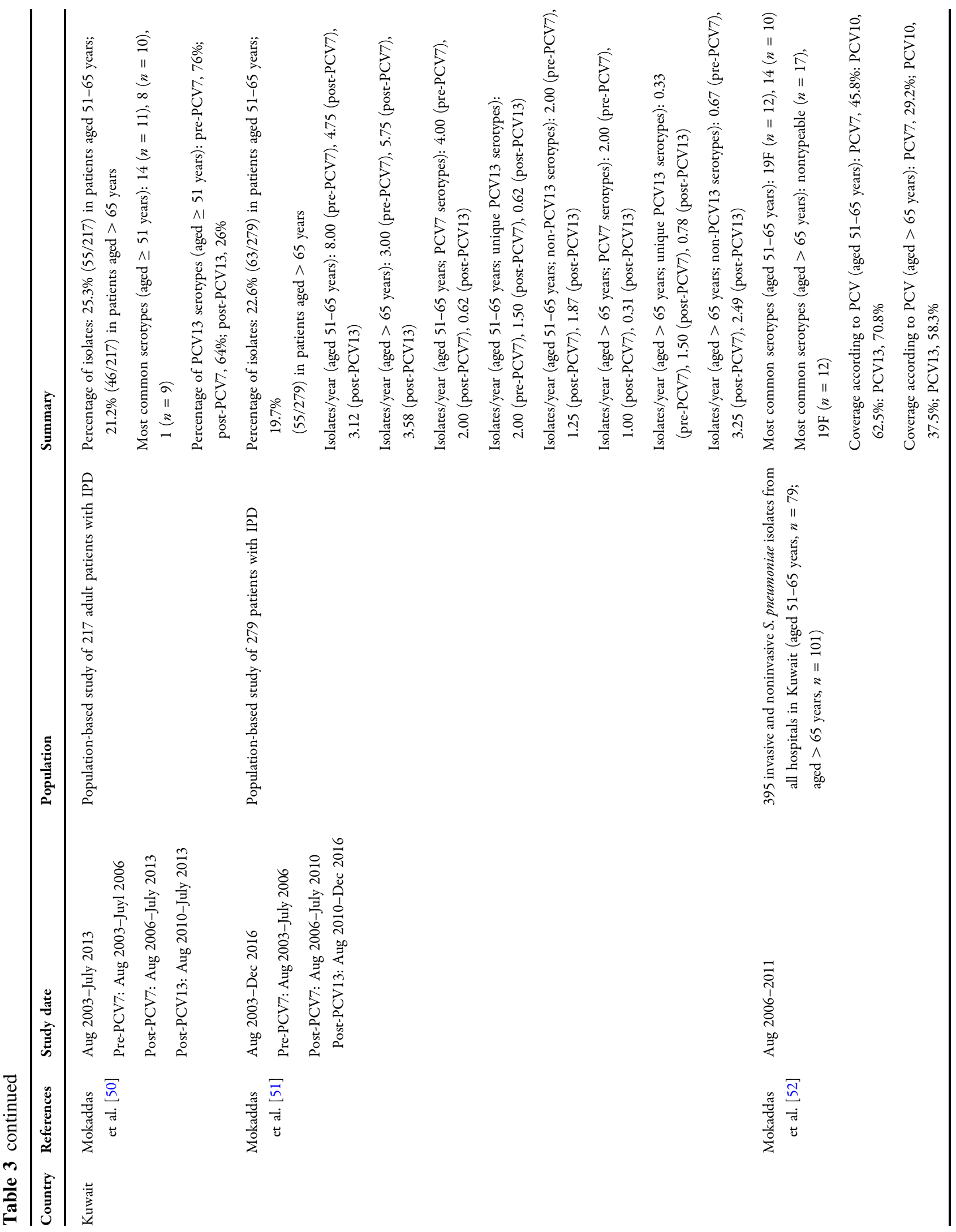




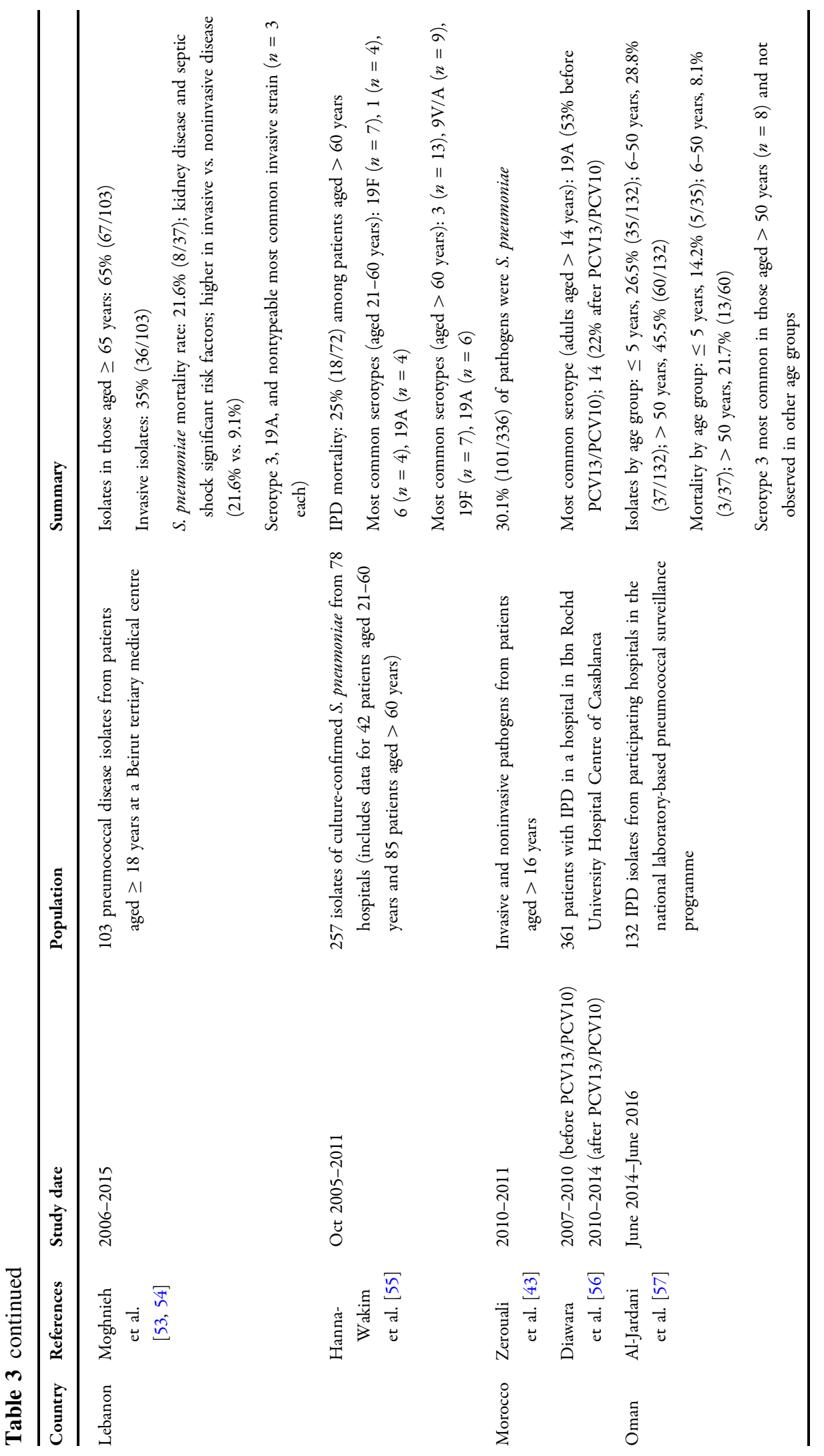




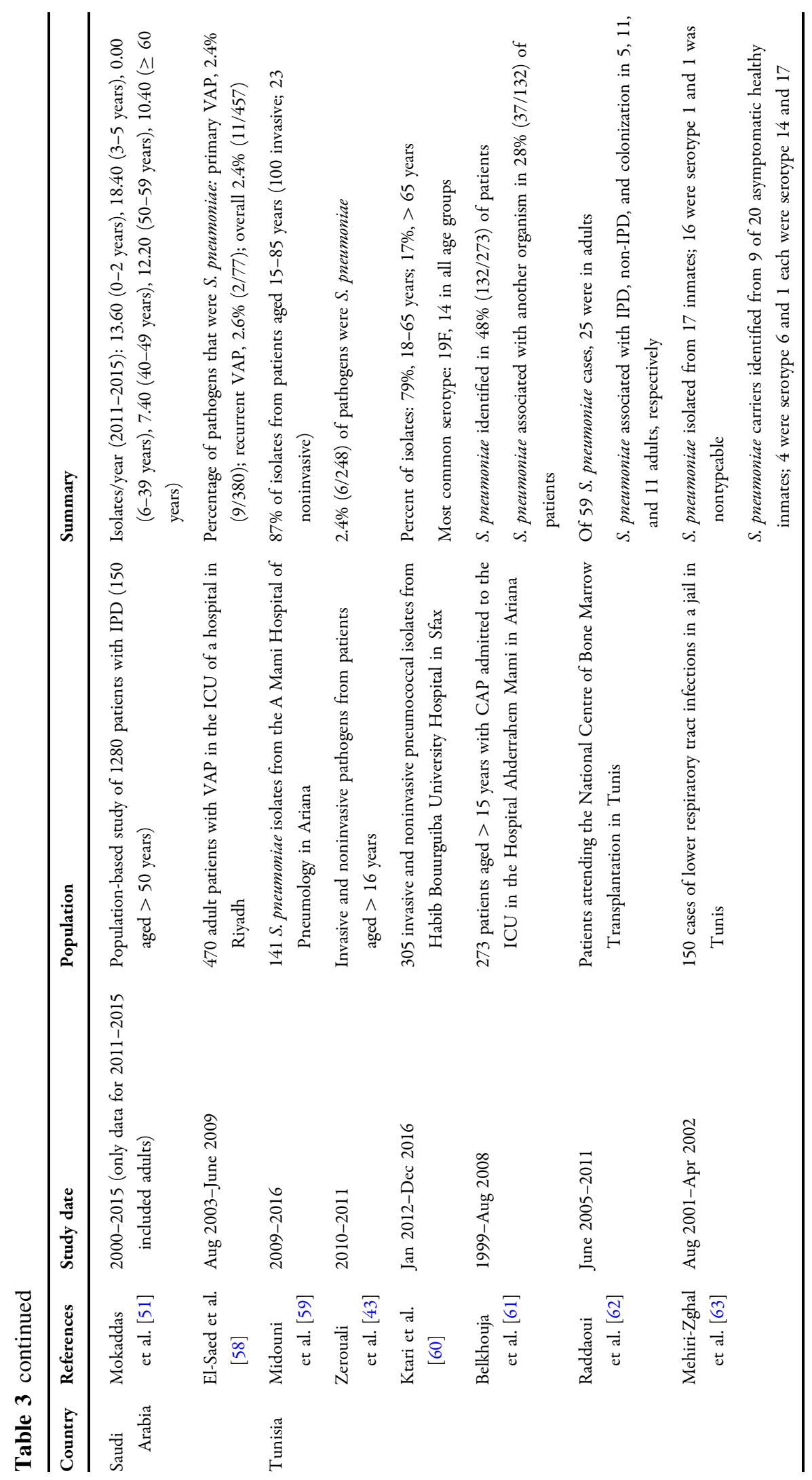




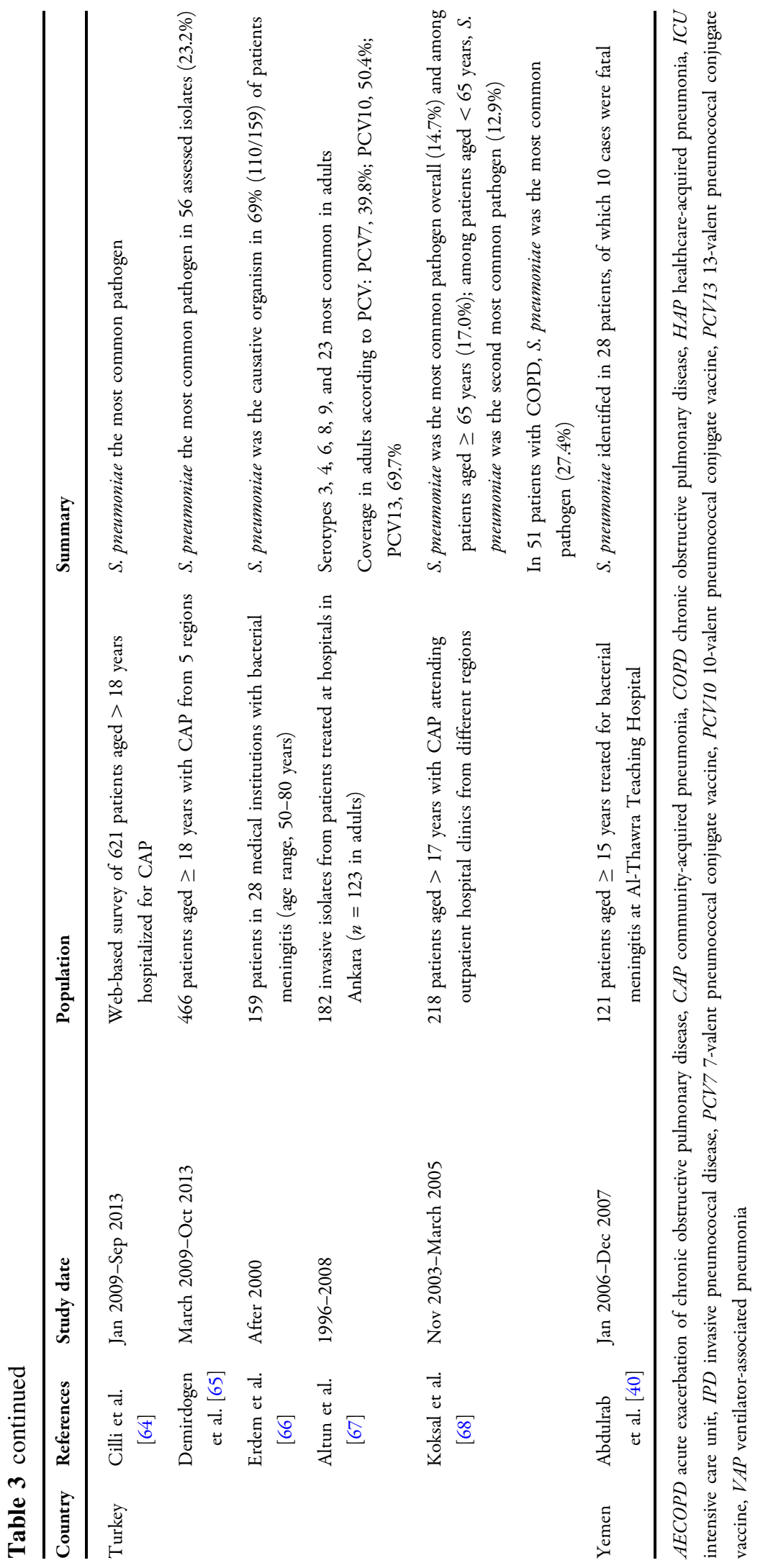


offered to adults at high risk for pneumococcal disease. In this period, adults aged $>50$ years had the highest rates of IPD (45.5\%) and mortality $(21.7 \%)$ compared with individuals aged $\leq 5$ years $(26.5 \%$ and $14.2 \%$, respectively) and aged $6-50$ years $(28.8 \%$ and $8.1 \%)$. Additionally, serotype 3 was the most common in this age group and was not observed in other age groups; serotypes 12 and 15 were the most common overall.

Three of the population-based studies were from Kuwait and included a series of publications by Mokaddas and colleagues spanning data from 2003 to 2016 assessing IPD according to implementation of paediatric PCV programmes in the country (PCV7 introduced in 2006 and PCV13 in 2010 for children aged $<2$ years with catch-up programmes for those aged 2-5 years) [50-52]. The most recent of these publications provided consolidated data over this time period, with $42 \%$ of IPD isolates in Kuwait from 2003-2016 found to occur in adults aged $\geq 51$ years [51]. In individuals aged 51-65 years, progressive decreases over time were seen in the frequency of PCV7 serotypes $(4.00,2.00$, and 0.62 , isolates/year, respectively) and the six unique PCV13 serotypes $(2.00,1.50$, and 0.62 , isolates/year) from before PCV introduction to after PCV7 and then PCV13 introduction, while the frequency of non-PCV13 serotypes decreased after PCV7 introduction and then increased after PCV13 introduction (2.00, 1.25, and 1.87 isolates/year). In those aged $>65$ years, progressive decreases in the frequency of PCV7 serotypes were seen over the three time periods $(2.00,1.00$, and 0.31 isolates/year), while the frequency in the six unique PCV13 serotypes $(0.33,1.50$, and 0.78 isolates/year) and of non-PCV13 serotypes (0.67, 3.25, and 2.49 isolates/year) increased after PCV7 introduction and subsequently decreased after PCV13 introduction. A similar trend was observed in children aged $<2$ years (i.e., the target age group for vaccination, 3.00, 4.25 , and 2.49 isolates/year, respectively).

In this most recent publication by Mokaddas and colleagues, invasive pneumococcal isolates collected between 2000 and 2015 from hospital clinical laboratories in Saudi Arabia were also assessed [51]. However, only data from 2011 to
2015 included adult populations, which corresponded with PCV13 introduction into the NIP for children aged $<2$ years and with a catch-up programme for those aged 2-5 years. In the period after PCV13 implementation, the annual frequency of invasive pneumococcal isolates was $7.40,12.20$, and 10.40 isolates/year in those aged 40 to 49,50 to 59 , and $\geq 60$ years, respectively, compared with rates of 13.60 , 18.40 , and 0.00 in those aged 0 to 2,3 to 5 , and 6 to 39 years, respectively.

The final population-based study included national surveillance data on invasive pneumococcal isolates in Lebanon [55]. The study included data from a 6-year period (2005-2011). Mortality was highest among the eldest subjects (>60 years, 25\%), and the most common serotypes were $3,9 \mathrm{~V} / \mathrm{A}, 19 \mathrm{~F}$, and 19A. In this age group, PCV7, PCV10, and PCV13 coverage was $35 \%, 45 \%$, and $68 \%$, respectively, and was comparable to that in younger adults (aged 21 to 60 years).

The high burden of pneumococcal disease in adults observed in these national surveillance studies is generally supported by findings from smaller assessments of adults in the MENA region identified in the literature search [40, 43-47, 49, 51, 53, 54, 57-68]. Collectively, these data support the high burden of pneumococcal disease in MENA, particularly among older adults.

\section{Haemophilus influenzae}

Of the 35 articles retrieved in the HI literature search, 4 described HI epidemiology in adults and were thus included in the analysis (Fig. 1; Table 4) $[37,40,69,70]$. This included two publications from Turkey [69, 70] and single publications from Egypt [37] and Yemen [40]. None of the identified publications was population based [37, 40, 69, 70].

In a study of confirmed meningitis cases in an Egyptian hospital from 1997 to 2006, the percentage of cases attributed to Hib decreased throughout the study period and completely disappeared by 2004-2005 and reappeared in 2006 [37]. In individuals aged 18-60 years, 2.2\% of cases were attributed to Hib, whereas no cases 
Table 4 Summary of studies for Haemophilus influenzae

\begin{tabular}{|c|c|c|c|c|}
\hline Country & References & Study date & Population & Summary \\
\hline Egypt & $\begin{array}{l}\text { Mobarak } \\
\text { et al. } \\
\text { [37] }\end{array}$ & 1997-2006 & $\begin{array}{r}1210 \text { meningitis cases at Alexandria } \\
\text { Communicable Diseases Hospital }\end{array}$ & $\begin{array}{l}\text { Percentage of Hib cases across all ages } \\
\text { decreased over time } \\
\text { Hib was the causative pathogen in } \\
2.2 \% \text { and } 0 \% \text { of cases aged } 18-60 \\
\text { and }>60 \text { years, respectively }\end{array}$ \\
\hline \multirow[t]{2}{*}{ Turkey } & $\begin{array}{l}\text { Soyletir } \\
\text { et al. } \\
\text { [69] }\end{array}$ & $2011-2013$ & $\begin{array}{l}\text { Clinical respiratory isolates from } \\
\text { outpatients }\end{array}$ & $\begin{array}{l}56.6 \%(192 / 339) \text { of } H \text {. influenzae } \\
\text { isolates were from adults, and } 20.9 \% \\
(71 / 339) \text { were from elderly patients }\end{array}$ \\
\hline & $\begin{array}{l}\text { Çağlayan } \\
\text { Serin } \\
\text { et al. } \\
{[70]}\end{array}$ & $\begin{array}{c}\text { Feb-Dec } \\
2010\end{array}$ & $\begin{array}{l}55 \text { patients aged } \geq 18 \text { years hospitalized } \\
\text { with CAP at Ege University Faculty of } \\
\text { Medicine; diagnosis by conventional (i.e., } \\
\text { standard bacteriological culture) and } \\
\text { multiplex PCR compared }\end{array}$ & $\begin{array}{l}\text { H. influenzae: conventional methods, } \\
22 \% \text {; PCR methods, } 12 \% \\
\text { 36\% of patients had concomitant } H \text {. } \\
\text { influenzae and } S \text {. pneumoniae }\end{array}$ \\
\hline Yemen & $\begin{array}{l}\text { Abdulrab } \\
\text { et al. } \\
\text { [40] }\end{array}$ & $\begin{array}{l}\text { Jan } 2006- \\
\text { Dec } 2007\end{array}$ & $\begin{array}{l}121 \text { patients aged } \geq 15 \text { years treated for } \\
\text { bacterial meningitis }\end{array}$ & $\begin{array}{l}\text { H. influenzae was detected in } 6 / 59 \\
\text { patients who had CSF evaluation of } \\
\text { cultures } \\
\text { CFR in patients with } H \text {. influenzae } \\
\text { was } 16.6 \%\end{array}$ \\
\hline
\end{tabular}

CAP community-acquired pneumonia, CFR case fatality rate, CSF cerebrospinal fluid, Hib H. influenzae type B, PCR polymerase chain reaction

were observed in those $>60$ years old. Another hospital-based study was conducted from 2006-2007 and included patients aged $\geq 15$ years in Yemen admitted for acute bacterial meningitis [40]. HI was detected in 6 of 59 patients who received lumbar puncture for cultures; the CFR in these 6 patients was $16.6 \%$.

A study from Turkey of sterile and noninvasive $\mathrm{HI}$ isolates collected from outpatients from 2011 to 2013 found that $56.6 \%$ were from adult and $20.9 \%$ from elderly patients [69]. Another study from Turkey conducted in 2010 assessed conventional bacteriological culture and multiplex polymerase chain reaction (PCR) methodologies to determine the associated pathogen in adult patients hospitalized with communityacquired pneumonia (CAP) [70]. Using conventional methods, $22 \%$ of patients were determined to have HI-associated CAP, and multiplex PCR detected HI in $12 \%$ of patients. SP concomitant with HI was found in $36 \%$ of patients.

\section{DISCUSSION}

From the information analyzed in this literature review, adults in the MENA region appear to have a high burden of NM, SP, and HI disease. In addition, some consistencies with epidemiological data from other regions were noted. For instance, the limited data on meningococcal carriage that were identified are generally consistent with publications of other countries outside of the MENA region, with carriage rates between 1.4 and $14.2 \%$ reported across all ages in low- and middle-income countries of the Americas and Asia and up to $2 \%$ in Africa 
[71, 72]. Additionally, studies from western regions and sub-Saharan Africa have also reported an association between smoking and carriage [73-75].

Importantly, this literature review highlights the wide variability in the quality and paucity of data regarding the epidemiology of adult IBD in the MENA region. Elucidating the burden of adult VPD in MENA is necessary to guide vaccination strategies, reduce disease burden, and improve outcomes. The majority of countries in this region face significant hurdles related to implementation of vaccine programmes $[8,9]$. Critical to the understanding of adult disease burden within MENA is comprehensive and contemporary surveillance of VPD; however, such activities as well as vaccination programmes within MENA are variable and often limited, as described below [10].

\section{Existing Surveillance Programmes for IBD in the MENA Region}

Unfortunately, few MENA countries have mandatory IMD surveillance, with such activities largely focused on pilgrimages to the area $[10,76]$. In Algeria, meningococcal disease is notifiable and microbiological information is collected by the Algerian Pasteur Institute using network laboratories [76]. In Kuwait, the Ministry of Health initiated national surveillance of meningococcal disease in 1987 [38]. In Morocco, IMD surveillance is in partnership with the French Pasteur Institute [76]. Beginning in 1994, the Saudi Ministry of Health mandated the anonymous reporting of confirmed IMD cases [39]. Whereas meningitis cases in Lebanon are reported to the Ministry of Public Health, approximately $35 \%$ of cases in 2019 were unspecified [77]. Although there is mandatory reporting of meningococcal disease in Tunisia, a national surveillance network is not currently in place [76]. In Jordan, meningococcal disease is reported to the Ministry of Health [78]. Additionally, in the Abu Dhabi Emirate, meningitis reporting is mandatory, and electronic notification is required [79]. Accordingly, limited publicly available information is available on endemic epidemiology and burden of IMD in MENA.

The authors are not aware of mandatory surveillance programmes for pneumococcal and HI disease in the MENA region, which contributes to the challenges faced in measuring the true burden of disease in this region and in ascertaining rational preventive strategies [80].

\section{Existing Vaccination Programmes for IBD in the MENA Region}

Vaccines targeting the most common diseasecausing meningococcal serogroups are currently available, including monovalent, bivalent, and quadrivalent polysaccharide and conjugate vaccines against serogroups $\mathrm{A}, \mathrm{C}, \mathrm{W}$, and/or $\mathrm{Y}$ and protein-based vaccines against serogroup $\mathrm{B}$ $[13,14]$. No vaccines are available currently to protect against serogroup $\mathrm{X}$, which is a cause of epidemics in sub-Saharan Africa [81]. As of 2019, meningococcal vaccines are only included in the immunization schedules of Bahrain, Egypt, Iran, Kuwait, Oman, Qatar, Saudi Arabia, Syria, and the United Arab Emirates (UAE; Table S1) [14, 82]. No countries within the MENA region currently have routine adult IMD vaccination policies. However, highrisk individuals (e.g., pilgrims or travellers) are included in the schedules of Bahrain, Egypt, Oman, Qatar, Saudi Arabia, and the UAE. For instance, the Saudi Arabian government mandates pre-Hajj meningococcal vaccination 10 days before arrival at the ritual area for domestic individuals who have not been vaccinated in the last 5 years and for international pilgrims [82].

Two main types of pneumococcal vaccine are currently available: the PPSV23 and PCVs targeting 10 or 13 serotypes (PCV10 and PCV13; although PCV13 is the only PCV with indications for adults), the latter two vaccines replacing PCV7 [27, 83]. PPSV23 induces relatively short-term protection against IPD and is not effective in children aged $<2$ years, whereas PCVs stimulate a longer-term immune response and are effective from 6 weeks of age [25, 84, 85]. An important additional benefit of PCVs is reduced carriage rate of vaccine-type 
strains, which provides indirect protection to unvaccinated individuals [84]. However, replacement of vaccine serotypes with nonvaccine serotypes has been observed following PCV introduction [27]. PCVs are recommended by the World Health Organization (WHO) for use in infants worldwide [27], and some countries also recommend PCVs for older adults and adults with certain underlying conditions $[14,86]$. According to WHO data through most of 2018, PCV had been introduced in 145 countries, with an estimated global coverage of $47 \%$ for 3 vaccine doses [87]. PPSV23 is recommended in many countries for use in individuals with specific underlying medical conditions and in adults $\geq 65$ years of age, either alone or in series with PCV vaccination.

Of the MENA countries/states included in this review, Algeria, Bahrain, Djibouti, Iraq, Kuwait, Lebanon, Libya, Morocco, Oman, Palestine, Qatar, Saudi Arabia, Turkey, the UAE, and Yemen have included PCV in their infant NIP (Table S2) [14, 51, 53, 57, 88-96]. In addition to immunization of infants, PCV is provided in Qatar for adults aged $>50$ years and individuals at high risk of disease, in the Saudi Arabian NIP for adults aged $\geq 50$ years and for high-risk individuals aged $>6$ to $<50$ years, and in the UAE to high-risk groups [14, 93, 97]. Iran provides PCVs to high-risk groups only [14]. Several countries also provide PPSV23 to older adults and/or high-risk groups including Bahrain (adults $\geq 65$ years and high-risk groups $\geq 2$ years), Kuwait (high-risk adults), Qatar (high-risk groups $\geq 2$ years), Saudi Arabia (various high-risk populations individually or as part of a regimen with PCV13), and the UAE (high-risk groups) [14, 97].

Several monovalent and combination Hib polysaccharide conjugate vaccines are available; recommended schedules start as early as 6 weeks of age and may include three primary doses, two primary doses plus booster, or three primary doses plus booster [27]. Unvaccinated individuals aged $\geq 5$ years who do not have high-risk conditions are generally immune to Hib disease and do not require catch-up vaccination, and with the exception of a small number of specific situations, vaccinated individuals at increased risk for Hib disease do not require further vaccine doses [28]. According to WHO data, Hib vaccination had been introduced in 191 countries by the end of 2018 and had an estimated global coverage of $72 \%$ for three vaccine doses [98]. As of December 2019, all of the MENA countries included in this review provided Hib vaccination as part of their infant immunization schedule (Table S3) $[14,88]$.

\section{Knowledge Gaps and Guidance for Future Surveillance and Management Activities}

Although the limited contemporary data on the epidemiology of the three vaccine-preventable IBDs among adults in MENA are disappointing, they do emphasize the importance of improved surveillance for these diseases within the region. Comprehensive and contemporary surveillance activities are needed to identify emergence of new invasive strains including the emergence of new predominant serogroups or serotypes, to ascertain the direct and indirect effects of vaccination programmes, and to implement appropriate prevention and treatment strategies based on the unique needs and disease profile within the region.

Some methods to improve surveillance activities include mandating surveillance activities through healthcare authorities, utilizing electronic medical records and linking surveillance systems to quickly and accurately capture data, thoroughly training medical personnel on the importance of surveillance, and linking laboratory data with public health agencies. For the timely interpretation and consolidation of the increased data that will be accordingly accumulated, information and knowledge management systems would need to be implemented. Critical components of improved surveillance activities are commitment and cooperation both logistically and financially from local governments, the private sector, and global organizations, the latter of which should be directed at both low- and middle-income countries.

Another issue regarding the prevention of IBD among adults is that few low- and middleincome countries have included older adults in their vaccination programmes [2]. In addition, 
current WHO guidance on vaccination focuses on paediatric populations, and few recommendations exist regarding vaccination of adults. Even in high-income countries, adult vaccine uptake is low. This is despite the acknowledged benefits of vaccination of older adults, including decreasing burden of disease, improving AMR rates (as described further below), and targeting difficult-to-treat disease strains. Notably, implementation of vaccination programmes in adult populations will need to consider the necessary uptake of the vaccine, which will be affected by the specific vaccine, the target disease, characteristics of the population, and potential herd protection from existing paediatric programmes.

Health economic evaluations are a critical component in the implementation of vaccination programmes $[2,6]$. However, compared with evaluations among paediatric populations, health economic assessments of adult vaccination programmes beyond high-income countries are lacking, and existing assessment approaches might not capture outcomes of relevance to this population (e.g., economic benefits to the individual, household, and society) [2]. Herd protection of adult populations also complicates health economic evaluations of vaccination programmes. Developing guidance for assessing direct and indirect costs of preventing VPDs that disproportionately affect older adults is urgently needed.

For countries in the MENA region, providing affordable vaccines to at-risk populations can be challenging [8]. For instance, in MENA, there is fragmented demand and procurement, and only some countries qualify for Gavi funding. In addition, lower-middle-income countries face other financial challenges because of decreased sources of healthcare aid compared with low-income countries [6]. Although associated with paediatric vaccinations, UNICEF has been working in the region to improve access to affordable vaccines including pooled procurement tenders [8]. If successful, implementation of a similar strategy for adult vaccines might help address the financial and access constraints of such vaccination programmes.

Another critical component of vaccine uptake is the attitudes and choices of stakeholders, including the public, physicians, and healthcare authorities [4]. As public awareness of vaccinepreventable diseases can be low, which is associated with provision of inconsistent advice and recommendations by healthcare providers regarding the benefits of immunization of adults $[4,9]$, clearly addressing these gaps, such as by continually emphasizing the importance of vaccination, might improve vaccination rates. Such educational approaches can be broad or localized and should be tailored to the needs and characteristics of the particular region $[2,4]$. Consideration of the contribution of the private sector to these activities is needed, as private sector contribution to vaccination activities in the MENA region is limited or underreported [9]. Establishing vaccination advocates, increasing the focus of healthcare systems on the ageing population, and obtaining political commitment for vaccination have also been suggested as approaches to improve vaccine uptake [2].

Antimicrobial resistance is also a concern in the MENA region, including multidrug-resistant (MDR) organisms; for instance, a national-based assessment of AMR conducted in Oman found that MDR rates were highest in the youngest $(\leq 5$ years) and oldest ( $>50$ years) age groups [57]. AMR within the MENA region is thought to be attributed to inappropriate use of antimicrobials, lack of infection control measures, and mobilization of populations due to socioeconomic crises and armed conflicts [99]. Effective and widely implemented vaccination policies are also critical to address the problem of AMR, which is an increasing worldwide concern for many infectious diseases that are prevalent in healthcare and community settings [100]. In fact, inadequate measures to control and prevent the spread of infections contribute to increasing AMR rates. Vaccines not only decrease disease prevalence but also reduce the need for antimicrobial treatment, thus indirectly impacting AMR rates. The WHO accordingly prioritized AMR control through measures that include improved surveillance and control and prevention of infections. Whereas vaccine use in low-income countries, which are at highest risk of AMR, could lead to significant benefits, a paucity of data is available on the impact of vaccination on AMR in adults from 
low-income countries [2]. Therefore, commitment to assessing the effect of vaccination on AMR among adults in low-income countries, including those within the MENA region, is urgently needed.

Adequately addressing the issue of AMR also requires tackling barriers to implementation of these strategies. In the MENA region, this includes individual and healthcare system barriers [99]. For instance, individual barriers can include physician educational gaps on appropriate antibiotic use and physician reluctance to use unfamiliar antimicrobials. Healthcare system barriers in the MENA region include financial constraints and lack of sufficient administrative and management support for the implementation of antimicrobial stewardship programmes. Other countries, such as South Africa, have created programmes and policies to combat AMR and the increasing burden of infectious diseases [101]. Lessons from this South African approach emphasize the importance of enhanced surveillance, antimicrobial stewardship, and preventive approaches such as increased vaccination uptake and infection prevention and control.

\section{Strengths, Limitations, and Future Directions}

To the best of our knowledge, this is the only contemporary publication to broadly consider the epidemiology of vaccine-preventable IBD in adults within the MENA region. A limitation of our analysis is the scope of the literature search, which was restricted to English-language articles within databases accessed by PubMed. In addition, any literature published locally by government or healthcare authorities was not captured by this search strategy. However, it should be emphasized that the PubMed literature search likely included much of the data available on the epidemiology of NM, SP, and $\mathrm{HI}$ in adults in the MENA region, particularly those from large, contemporary, and population-based studies.

It is also important to emphasize that the comparison of data among countries and studies is limited because of differences among studies that could affect results such as populations assessed, sampling techniques, and time periods within the study as well as differences in vaccination policies, healthcare systems, and type of surveillance activities (if any) employed in each country. These differences and the small number of studies and sample sizes limited comparisons among studies and countries. This was particularly notable for $\mathrm{HI}$, in which no population-based studies were identified, and the included studies had small sample sizes and varied in the types of end points assessed $[37,40,69,70]$.

In this context, future studies within the region that utilize a structured design, population-based assessments, and sensitive detection methods are needed. In addition, future studies within the MENA region should focus on overuse and abuse of antibiotics, use of PCR as a tool to diagnose infections earlier, and investigation of the effect of vaccination programmes on MDR.

\section{ACKNOWLEDGEMENTS}

Funding. This work and the article processing charges, including the journal's Rapid Service Fee, were sponsored by Pfizer Inc.

Authorship. All named authors meet the International Committee of Medical Journal Editors (ICMJE) criteria for authorship for this manuscript and take responsibility for the integrity of the data and accuracy of the analysis.

Medical Writing, Editorial, and Other Assistance. Medical writing support was provided by Emily Stackpole, PhD, and Tricia Newell, PhD, of ICON plc (North Wales, PA) and was funded by Pfizer Inc.

Disclosures. Nadine Al Akoury and Hammam Haridy are Pfizer employees and may hold stock or stock options. Abdul Rahman Bizri, Abdulhakeem Althaqafi, Nawal Kaabi, and Nathir Obeidat have nothing to disclose. 
Compliance with Ethics Guidelines. The article is based on previously conducted studies and does not contain any studies with human participants or animals performed by any of the authors.

Open Access. This article is licensed under a Creative Commons Attribution-NonCommercial 4.0 International License, which permits any noncommercial use, sharing, adaptation, distribution, and reproduction in any medium or format, as long as you give appropriate credit to the original author(s) and the source, provide a link to the Creative Commons licence, and indicate if changes were made. The images or other third party material in this article are included in the article's Creative Commons licence, unless indicated otherwise in a credit line to the material. If material is not included in the article's Creative Commons licence and your intended use is not permitted by statutory regulation or exceeds the permitted use, you will need to obtain permission directly from the copyright holder. To view a copy of this licence, visit http://creativecommons.org/ licenses/by-nc/4.0/.

\section{REFERENCES}

1. Centers for Disease Control and Prevention. Ten great public health achievements-worldwide, 2001-2010. MMWR Morb Mortal Wkly Rep. 2011;60:814-8.

2. Teresa Aguado M, Barratt J, Beard JR, et al. Report on WHO meeting on immunization in older adults: Geneva, Switzerland, 22-23 March 2017. Vaccine. 2018;36:921-31.

3. Swanson KA, Schmitt HJ, Jansen KU, Anderson AS. Adult vaccination. Hum Vaccin Immunother. 2015;11:150-5.

4. de Gomensoro E, Del Giudice G, Doherty TM. Challenges in adult vaccination. Ann Med. 2018;50: 181-92.

5. Esposito S, Bonanni P, Maggi S, et al. Recommended immunization schedules for adults: clinical practice guidelines by the ESCMID Vaccine Study Group (EVASG), European Geriatric Medicine Society (EUGMS) and the World Association for Infectious Diseases and Immunological Disorders (WAidid). Hum Vaccin Immunother. 2016;12:1777-94.
6. Turner HC, Thwaites GE, Clapham HE. Vaccinepreventable diseases in lower-middle-income countries. Lancet Infect Dis. 2018;18:937-9.

7. Restrepo-Mendez MC, Barros AJ, Wong KL, et al. Inequalities in full immunization coverage: trends in low- and middle-income countries. Bull World Health Organ. 2016;94:794-805B.

8. Kaddar M, Saxenian H, Senouci K, Mohsni E, SadrAzodi N. Vaccine procurement in the Middle East and North Africa region: challenges and ways of improving program efficiency and fiscal space. Vaccine. 2019;37:3520-8.

9. Sadr-Azodi N, DeRoeck D, Senouci K. Breaking the inertia in coverage: mainstreaming under-utilized immunization strategies in the Middle East and North Africa region. Vaccine. 2018;36:4425-32.

10. Ceyhan M, Anis S, Htun-Myint L, et al. Meningococcal disease in the Middle East and North Africa: an important public health consideration that requires further attention. Int J Infect Dis. 2012;16: e574-82.

11. Chiappini E, Inturrisi F, Orlandini E, de Martino M, de Waure C. Hospitalization rates and outcome of invasive bacterial vaccine-preventable diseases in Tuscany: a historical cohort study of the 2000-2016 period. BMC Infect Dis. 2018;18:396.

12. Murray J, Agocs M, Serhan F, et al. Global invasive bacterial vaccine-preventable diseases surveillance-2008-2014. MMWR Morb Mortal Wkly Rep. 2014;63:1159-62.

13. Borrow R, Alarcon P, Carlos J, et al. The Global Meningococcal Initiative: global epidemiology, the impact of vaccines on meningococcal disease and the importance of herd protection. Expert Rev Vaccines. 2017;16:313-28.

14. World Health Organization. 2019. WHO vaccinepreventable diseases: monitoring system. 2019 global summary. Available at: http://apps.who.int/ immunization_monitoring/globalsummary/ schedules. Accessed date 8 July 2020

15. UNICEF Middle East and North Africa. 2020. Where we work. Available at: https://www.unicef.org/ mena/where-we-work. Accessed date 8 July 2020

16. The World Bank. Middle East and North Africa. Available at: https://data.worldbank.org/region/ middle-east-and-north-africa?view=chart. Accessed date 8 July 2020

17. International Monetary Fund. World Economic Outlook, April 2018: Cyclical Upswing, Structural Change. Available at: https://www.imf.org/en/ Publications/WEO/Issues/2018/03/20/world- 
economic-outlook-april-2018. Accessed date 8 July 2020

18. Martinon-Torres F. Deciphering the burden of meningococcal disease: conventional and underrecognized elements. J Adolesc Health. 2016;59: S12-20.

19. Pelton SI. The global evolution of meningococcal epidemiology following the introduction of meningococcal vaccines. J Adolesc Health. 2016;59: S3-11.

20. World Health Organization. Meningococcal meningitis. Available at: http://www.who.int/en/ news-room/fact-sheets/detail/meningococcalmeningitis. Accessed date 8 July 2020

21. Peterson ME, Li Y, Bita A, et al. Meningococcal serogroups and surveillance: a systematic review and survey. J Glob Health. 2019;9:010409.

22. Yildirim I, Shea KM, Pelton SI. Pneumococcal disease in the era of pneumococcal conjugate vaccine. Infect Dis Clin North Am. 2015;29:679-97.

23. European Centre for Disease Prevention and Control. 2020. Disease factsheet about pneumococcal disease. Available at: https://www.ecdc.europa.eu/ en/pneumococcal-disease/facts. Accessed date 8 July 2020

24. Centers for Disease Control and Prevention. 2017. Active Bacterial Core Surveillance (ABCs) Report: Streptococcus pneumoniae, 2017. Available at: https:// www.cdc.gov/abcs/reports-findings/survreports/ spneu17.html. Accessed date 8 July 2020

25. Centers for Disease Control and Prevention.2020. Chapter 17: Pneumococcal Disease. Public Health Foundation. Available at: https://www.cdc.gov/ vaccines/pubs/pinkbook/pneumo.html. Accessed date 8 July 2020

26. Zhang D, Petigara T, Yang X. Clinical and economic burden of pneumococcal disease in US adults aged 19-64 years with chronic or immunocompromising diseases: an observational database study. BMC Infect Dis. 2018;18:436.

27. World Health Organization. Haemophilus Influenzae. Vaccine-Preventable Diseases: Surveillance Standards. Available at: https://www.who.int/ immunization/monitoring_surveillance/burden/ vpd/WHO_SurveillanceVaccinePreventable_05_ HaemophilusInfluenzae_R2.pdf?ua=1. Accessed date 8 July 2020

28. Briere EC, Rubin L, Moro PL, et al. Prevention and control of Haemophilus influenzae type B disease: recommendations of the Advisory Committee on
Immunization Practices (ACIP). MMWR Recomm Rep. 2014;63:1-14.

29. Soeters HM, Blain A, Pondo T, et al. Current epidemiology and trends in invasive Haemophilus influenzae disease-United States, 2009-2015. Clin Infect Dis. 2018;67:881-9.

30. Heinz E. The return of Pfeiffer's bacillus: rising incidence of ampicillin resistance in Haemophilus influenzae. Microb Genom. 2018. https://doi.org/10. 1099/mgen.0.000214.

31. Whittaker R, Economopoulou A, Dias JG, et al. Epidemiology of invasive Haemophilus influenzae disease, Europe, 2007-2014. Emerg Infect Dis. 2017;23:396-404.

32. Ladhani S, Slack MP, Heath PT, et al. Invasive Haemophilus influenzae disease, Europe, 1996-2006. Emerg Infect Dis. 2010;16:455-63.

33. Heydari B, Khalili H, Karimzadeh I, Emadi-Kochak H. Clinical, paraclinical, and antimicrobial resistance features of community-acquired acute bacterial meningitis at a large infectious diseases ward in Tehran. Iran. Iran J Pharm Res. 2016;15:347-54.

34. Sadeghi M, Ahmadrajabi R, Dehesh T, Saffari F. Prevalence of meningococcal carriage among male university students living in dormitories in Kerman, southeast of Iran. Pathog Glob Health. 2018;112: 329-33.

35. Kepenekli Kadayifci E, Guneser Merdan D, Soysal A, et al. Prevalence of Neisseria meningitidis carriage: a small-scale survey in Istanbul. Turkey J Infect Dev Ctries. 2016;10:413-7.

36. Tekin RT, Dinleyici EC, Ceyhan M, et al. The prevalence, serogroup distribution and risk factors of meningococcal carriage in adolescents and young adults in Turkey. Hum Vaccin Immunother. 2017;13:1182-9.

37. Mobarak EI. Trend, features and outcome of meningitis in the Communicable Diseases hospital, Alexandria, Egypt, 1997-2006. J Egypt Public Health Assoc. 2012;87:16-23.

38. Husain EH, Barakat M, Al-Saleh M. Trends and variations in the epidemiology of meningococcal disease in Kuwait 1987-2013. J Infect Public Health. $2015 ; 8: 441-7$.

39. Memish Z, Al Hakeem R, Al Neel O, et al. Laboratory-confirmed invasive meningococcal disease: effect of the Hajj vaccination policy, Saudi Arabia, 1995 to 2011. Euro Surveill. 2013;1:18.

40. Abdulrab A, Algobaty F, Salem AK, Mohammed YA. Acute bacterial meningitis in adults: a hospital 
based study in Yemen. Jpn J Infect Dis. 2010;63: 128-31.

41. Stephens DS, Greenwood B, Brandtzaeg P. Epidemic meningitis, meningococcaemia, and Neisseria meningitidis. Lancet. 2007;369:2196-210.

42. Stephens DS. Biology and pathogenesis of the evolutionarily successful, obligate human bacterium Neisseria meningitidis. Vaccine. 2009;27:B71-7.

43. Zerouali K, Ramdani-Bouguessa N, Boye C, Hammami A, Active 2 Group. Multicentric study in five African countries of antibiotic susceptibility for three main pathogens: Streptococcus pneumoniae, Staphylococcus aureus, and Pseudomonas aeruginosa. J Chemother. 2016;28:266-72.

44. El-Sokkary RH, Ramadan RA, El-Shabrawy M, et al. Community acquired pneumonia among adult patients at an Egyptian university hospital: bacterial etiology, susceptibility profile and evaluation of the response to initial empiric antibiotic therapy. Infect Drug Resist. 2018;11:2141-50.

45. Agmy G, Mohamed S, Gad Y, et al. Bacterial profile, antibiotic sensitivity and resistance of lower respiratory tract infections in upper egypt. Mediterr J Hematol Infect Dis. 2013;5:e2013056.

46. El Attar MM, Zaghloup MZ, Elmenoufr HS. Role of periodontitis in hospital-acquired pneumonia. East Mediterr Health J. 2010;16:563-9.

47. Saeed N, AlAnsari H, AlKhawaja S, et al. Trend of bacterial meningitis in Bahrain from 1990 to 2013 and effect of introduction of new vaccines. East Mediterr Health J. 2016;22:175-82.

48. Farshad AA, Enferadi M, Bakand S, Jamshidi Orak R, Mirkazemi R. Penicillin dust exposure and penicillin resistance among pharmaceutical workers in Tehran. Iran Int J Occup Environ Health. 2016;22: 218-23.

49. Naderi H, Sheybani F, Sarvghad M, Meshkat Z, Jabbari NM. Etiological diagnosis of community-acquired pneumonia in adult patients: a prospective hospital-based study in Mashhad, Iran. Jundishapur J Microbiol. 2015;8:e22780.

50. Mokaddas E, Albert MJ. Serotype distribution and penicillin-non-susceptibility of Streptococcus pneumoniae causing invasive diseases in Kuwait: a 10-year study of impact of pneumococcal conjugate vaccines. Expert Rev Vaccines. 2016;15:1337-45.

51. Mokaddas EM, Shibl AM, Elgouhary A, Elsobky M. Effect of the introduction of pneumococcal conjugate vaccines on serotype prevalence in Kuwait and Saudi Arabia. Vaccine. 2018;36:6442-8.
52. Mokaddas E, Albert MJ. Impact of pneumococcal conjugate vaccines on burden of invasive pneumococcal disease and serotype distribution of Streptococcus pneumoniae isolates: an overview from Kuwait. Vaccine. 2012;30(suppl 6):G37-40.

53. Moghnieh R, Tamim H, Awad L, et al. Epidemiology of invasive and non-invasive pneumococcal infections in hospitalised adult patients in a Lebanese medical centre, 2006-2015. J Infect Public Health. 2019. https://doi.org/10.1016/j.jiph.2019.03.003.

54. Moghnieh R, Awad L, Abdallah D, et al. Epidemiology of pneumococcal infections in hospitalised adult patients in Lebanon with a highlight on noninvasive disease. J Infect Dev Ctries. 2018;12:20S.

55. Hanna-Wakim R, Chehab H, Mahfouz I, et al. Epidemiologic characteristics, serotypes, and antimicrobial susceptibilities of invasive Streptococcus pneumoniae isolates in a nationwide surveillance study in Lebanon. Vaccine. 2012;30(suppl 6): G11-7.

56. Diawara I, Barguigua A, Katfy K, et al. Molecular characterization of penicillin non-susceptible Streptococcus pneumoniae isolated before and after pneumococcal conjugate vaccine implementation in Casablanca. Morocco Ann Clin Microbiol Antimicrob. 2017;16:23.

57. Al-Jardani A, Al Rashdi A, Al Jaaidi A, et al. Serotype distribution and antibiotic resistance among invasive Streptococcus pneumoniae from Oman post 13-valent vaccine introduction. Int $\mathrm{J}$ Infect Dis. 2019;85:135-40.

58. El-Saed A, Balkhy HH, Al-Dorzi HM, et al. Acinetobacter is the most common pathogen associated with late-onset and recurrent ventilator-associated pneumonia in an adult intensive care unit in Saudi Arabia. Int J Infect Dis. 2013;17:e696-701.

59. Midouni B, Mehiri E, Ghariani A, et al. Genetic diversity of Streptococcus pneumoniae in Tunisia. Int J Antimicrob Agents. 2019;53:63-9.

60. Ktari S, Jmal I, Mroua M, et al. Serotype distribution and antibiotic susceptibility of Streptococcus pneumoniae strains in the south of Tunisia: a five-year study (2012-2016) of pediatric and adult populations. Int J Infect Dis. 2017;65:110-5.

61. Belkhouja K, Ben Romdhane K, Ghariani A, et al. Severe pneumococcal community-acquired pneumonia admitted to medical Tunisian ICU. J Infect Chemother. 2012;18:324-31.

62. Raddaoui A, Simões AS, Baaboura R, et al. Serotype distribution, antibiotic resistance and clonality of streptococcus pneumoniae isolated from 
immunocompromised patients in Tunisia. PLoS ONE. 2015;10:e0140390.

63. Mehiri-Zghal E, Decousser JW, Mahjoubi W, et al. Molecular epidemiology of a Streptococcus pneumoniae serotype 1 outbreak in a Tunisian jail. Diagn Microbiol Infect Dis. 2010;66:225-7.

64. Cilli A, Sayiner A, Celenk B, et al. Antibiotic treatment outcomes in community-acquired pneumonia. Turk J Med Sci. 2018;48:730-6.

65. Demirdogen Cetinoglu E, Uzaslan E, Sayiner A, et al. Pneumococcal and influenza vaccination status of hospitalized adults with community acquired pneumonia and the effects of vaccination on clinical presentation. Hum Vaccin Immunother. 2017;13:2072-7.

66. Erdem H, Kilic S, Coskun O, et al. Community-acquired acute bacterial meningitis in the elderly in Turkey. Clin Microbiol Infect. 2010;16:1223-9.

67. Altun HU, Hascelik G, Gür D, Eser ÖK. Invasive pneumococci before the introduction of pneumococcal conjugate vaccine in Turkey: antimicrobial susceptibility, serotype distribution, and molecular identification of macrolide resistance. J Chemother. $2015 ; 27: 74-9$

68. Köksal I, Ozlü T, Bayraktar O, et al. Etiological agents of community-acquired pneumonia in adult patients in Turkey; a multicentric, cross-sectional study. Tuberk Toraks. 2010;58:119-27.

69. Soyletir G, Altinkanat G, Gur D, et al. Results from the survey of antibiotic resistance (SOAR) 2011-13 in Turkey. J Antimicrob Chemother. 2016;71(suppl 1):i71-83.

70. Caglayan Serin D, Pullukcu H, Cicek C, et al. Bacterial and viral etiology in hospitalized community acquired pneumonia with molecular methods and clinical evaluation. J Infect Dev Ctries. 2014;8: 510-8.

71. Peterson ME, Li Y, Shanks H, et al. Serogroupspecific meningococcal carriage by age group: a systematic review and meta-analysis. BMJ Open. $2019 . \quad$ https://doi.org/10.1136/bmjopen-2018024343.

72. Serra L, Presa J, Christensen H, Trotter C. Carriage of Neisseria Meningitidis in low and middle income countries of the Americas and Asia: a review of the literature. Infect Dis Ther. 2020;9:209-40.

73. Bruce MG, Rosenstein NE, Capparella JM, et al. Risk factors for meningococcal disease in college students. JAMA. 2001;286:688-93.
74. MacLennan J, Kafatos G, Neal K, et al. Social behavior and meningococcal carriage in British teenagers. Emerg Infect Dis. 2006;12:950-7.

75. Cooper LV, Robson A, Trotter CL, et al. Risk factors for acquisition of meningococcal carriage in the African meningitis belt. Trop Med Int Health. 2019;24:392-400.

76. Borrow R, Caugant DA, Ceyhan M, et al. Meningococcal disease in the Middle East and Africa: findings and updates from the Global Meningococcal Initiative. J Infect. 2017;75:1-11.

77. Ministry of Public Health, Lebanon. Meningitis Surveillance. Available at: https://www.moph.gov. lb/userfiles/files/Esu_data/Esu_currentyear/ Meningitis2019.htm. Accessed date 10 July 2020

78. Jordan Ministry of Health. The epidemiological situation. Available at: https://www.moh.gov.jo/ Pages/viewpage.aspx?pageID=177. Accessed date 22222020

79. Department of Health ADE. Communicable diseases bulletin. Available at: https://doh.gov.ae/-/media/ B47B39F959744517BB8C65B91D41CEBE.ashx. Accessed date 16 July 2020

80. Hausdorff WP, Hajjeh R, Al-Mazrou A, et al. The epidemiology of pneumococcal, meningococcal, and Haemophilus disease in the Middle East and North Africa (MENA) region-current status and needs. Vaccine. 2007;25:1935-44.

81. Alderson MR, LaForce FM, Sobanjo-Ter Meulen A, et al. Eliminating meningococcal epidemics from the African meningitis belt: the case for advanced prevention and control using next-generation meningococcal conjugate vaccines. J Infect Dis. 2019;220:S274-8

82. Ministry of Health KoSA (2019) Health requirements and recommendations for travellers to Saudi Arabia for Hajj and Umrah

83. World Health Organization. Pneumococcal vaccines WHO position paper-2012. Wkly Epidemiol Rec. 2012;87:129-44.

84. Weiser JN, Ferreira DM, Paton JC. Streptococcus pneumoniae: transmission, colonization and invasion. Nat Rev Microbiol. 2018;16:355-67.

85. Papadatou I, Tzovara I, Licciardi PV. The role of serotype-specific immunological memory in pneumococcal vaccination: current knowledge and future prospects. Vaccines (Basel). 2019;7:1.

86. Matanock A, Lee G, Gierke R, et al. Use of 13-valent pneumococcal conjugate vaccine and 23-valent pneumococcal polysaccharide vaccine among 
adults aged $\geq 65$ years: updated recommendations of the Advisory Committee on Immunization Practices. MMWR Morb Mortal Wkly Rep. 2019;68: 1069-75.

87. World Health Organization. Immunization coverage. Key facts. Available at: https://www.who.int/ news-room/fact-sheets/detail/immunizationcoverage. Accesseddate 8 July 2020

88. World Health Organization (2016) UNICEF. State of Palestine: WHO and UNICEF estimates of immunization coverage

89. Pugh SJ, Fletcher MA, Charos A, et al. Cost-effectiveness of the pneumococcal conjugate vaccine (10- or 13-valent) versus no vaccination for a national immunization program in Tunisia or Algeria. Infect Dis Ther. 2019;8:63-74.

90. Republic of Djibouti. National Program of Immunization Comprehensive Plan (CMYP) 2011-2015 Djibouti. Available at: https://www.gavi.org/sites/ default/files/document/comprehensive-multi-yearplan-for-2011-2015pdf.pdf. Accessed date 8 July 2020

91. Ezoji K, Yaghoubi M, Nojomi M, et al. Cost-effectiveness of introducing the pneumococcal conjugate vaccine for children under 5 years in the Islamic Republic of Iran. East Mediterr Health J. 2019;25:686-97.

92. World Health Organization (2019) High level meeting on cost efficiency in procurement of vaccines and quality data coverage of vaccination in Iraq. Meeting minutes

93. Feldman C, Abdulkarim E, Alattar F, et al. Pneumococcal disease in the Arabian Gulf: recognizing the challenge and moving toward a solution. J Infect Public Health. 2013;6:401-9.

94. Abu Seir R, Azmi K, Hamdan A, et al. Comparison of early effects of pneumococcal conjugate vaccines:
PCV7, PCV10 and PCV13 on Streptococcus pneumoniae nasopharyngeal carriage in a population based study; the Palestinian-Israeli Collaborative Research (PICR). PLoS ONE. 2018;13:e0206927.

95. Soysal A, Karabag-Yilmaz E, Kepenekli E, et al. The impact of a pneumococcal conjugate vaccination program on the nasopharyngeal carriage, serotype distribution and antimicrobial resistance of Streptococcus pneumoniae among healthy children in Turkey. Vaccine. 2016;34:3894-900.

96. Government of Dubai. Immunization Guidelines. Available at: https://www.dha.gov.ae/Documents/ HRD/Immunization\%20Guidelines.pdf. Accessed date 8 July 2020

97. Alharbi NS, Al-Barrak AM, Al-Moamary MS, et al. The Saudi Thoracic Society pneumococcal vaccination guidelines-2016. Ann Thorac Med. 2016;11: 93-102.

98. World Health Organization. Global Health Observatory (GHO) data (2020) Haemophilus influenzae type $\mathrm{B}$ third dose (Hib3) immunization coverage. Available at: https://www.who.int/gho/ immunization/Hib/en/. Accessed date 8 July 2020

99. Dandachi I, Chaddad A, Hanna J, Matta J, Daoud Z. Understanding the epidemiology of multi-drug resistant gram-negative bacilli in the Middle East using a one health approach. Front Microbiol. 2019;10:1941.

100. World Health Organization (2020) The evolving threat of antimicrobial resistance. Options for action. Available at: https://apps.who.int/iris/ bitstream/handle/10665/44812/9789241503181_ eng.pdf; jsessionid= 21019419258307673135127EFD46EE5D?sequence $=$ 1. Accessed date 8 July 2020

101. Mendelson M, Matsoso MP. The World Health Organization Global Action Plan for antimicrobial resistance. S Afr Med J. 2015;105:325. 